Goldschmidt 2021 Abstract

https://doi.org/10.7185/gold2021.7847

\section{Microscopic investigations of uranium uptake by rhodochrosite}

\section{SURYA SUJATHAN AND ABHAS SINGH}

Indian Institute of Technology Kanpur

Presenting Author: suryaj@iitk.ac.in

Widespread contamination of uranium (U) in groundwaters of India has gained attention in recent years. Most studies point toward a geogenic origin of $\mathrm{U}$, but the exact forms of $\mathrm{U}$ and their release mechanisms are not clear. Our recent investigation on oxic-anoxic Indian groundwaters indicated high probability of occurrence of elevated $U$ in the presence of elevated manganese $(\mathrm{Mn})$, whose concentrations seemed to be controlled by rhodochrosite $\left(\mathrm{MnCO}_{3}\right)$. While several environmentally-relevant carbonate minerals (e.g. $\mathrm{CaCO}_{3}, \mathrm{SrCO}_{3}, \mathrm{BaCO}_{3}$ ) have been previously reported to sequester U(VI), such capability of rhodochrosite is not known. In this contribution, U uptake during rhodochrosite crystal growth was investigated under completely mixed batch conditions. U(VI) over the concentration range of $10-500 \mu \mathrm{M}$ was added to reactors, previously containing solutions with $10 \mathrm{mM} \mathrm{Mn}$ and $10 \mathrm{mM}$ dissolved inorganic carbonate (DIC). System conditions were supersaturated with respect to rhodochrosite, but undersaturated with respect to any U-bearing solid. The reactors were closed, sealed, and kept on a rotary shaker at $110 \mathrm{rpm}$ at room temperature $\left(25^{\circ} \mathrm{C}\right)$. Pre- and post-experimental aqueous characterization of samples revealed up to $\sim 50 \%$ decrease in $U$ (Figure 1a). Scanning electron microscopy-energy-dispersive X-ray scattering (SEM-EDS; Figure 1b) and X-ray diffraction (XRD; Figure 1c) on precipitated solids confirmed the presence of rhodochrosite. No U-bearing solid phases were detected, consistent with the undersaturated state indicated by saturation indices. Also, the possibility of redox conversion of U(VI) to U(IV) by Mn was thermodynamically unfavorable. To investigate the nature of $U$ sequestration, detailed characterizations of the precipitated solids from batch experiments were performed using Fourier-transform infrared spectroscopy, Raman spectroscopy, X-ray photoelectron spectroscopy and transmission electron microscopy. Additionally, adsorptive uptake of $U$ was investigated by performing experiments at variable solid-to-liquid ratios of rhodochrosite. The sorption data were modelled to determine intrinsic surface stability constants for $U$ adsorption using surface complexation modelling. The results from these microscopic and macroscopic investigations will be discussed to elucidate the mechanism of $U$ uptake on rhodochrosite.

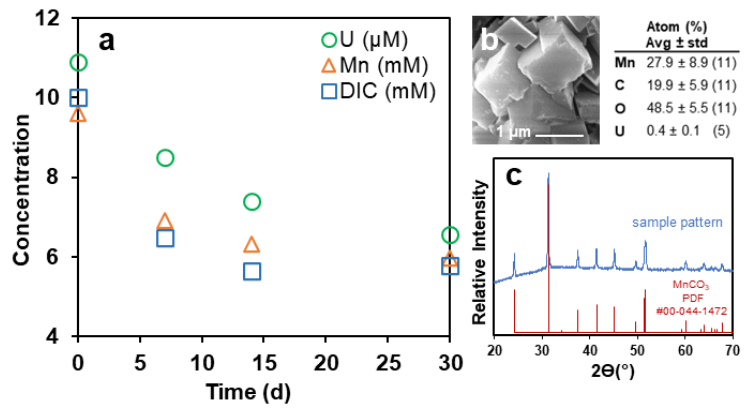

Figure1: (a) Total aqueous concentrations of Mn, DIC, and U with time for reactor with $10 \mu \mathrm{M}$ initial U; (b) W-SEM images and (c) XRD patterns of reactor with $10 \mu \mathrm{M}$ initial U; (b) W-SEM images and (c) XRD patterns
precipitated solids collected after $30 \mathrm{~d}$ from batch reactors with $10 \mu \mathrm{M}$ initial $\mathrm{U}$. 